\title{
Atomic-Scale Patterning of Arsenic in Silicon by Scanning Tunneling Microscopy
}

Taylor J. Z. Stock,* Oliver Warschkow, Procopios C. Constantinou, Juerong Li, Sarah Fearn, Eleanor Crane, Emily V. S. Hofmann, Alexander Kölker, David R. McKenzie, Steven R. Schofield, and Neil J. Curson*

Cite This: https://dx.doi.org/10.1021/acsnano.9b08943

Read Online

ABSTRACT: Over the past two decades, prototype devices for future classical and quantum computing technologies have been fabricated by using scanning tunneling microscopy and hydrogen resist lithography to position phosphorus atoms in silicon with atomic-scale precision. Despite these successes, phosphine remains the only donor precursor molecule to have been demonstrated as compatible with the hydrogen resist lithography technique. The potential benefits of atomic-scale placement of alternative dopant species have, until now, remained unexplored. In this work, we demonstrate the successful fabrication of atomic-scale structures of arsenic-insilicon. Using a scanning tunneling microscope tip, we pattern a monolayer hydrogen mask to selectively place arsenic atoms on
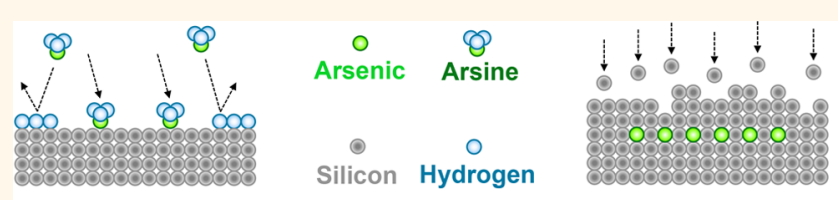

the $\mathrm{Si}(001)$ surface using arsine as the precursor molecule. We fully elucidate the surface chemistry and reaction pathways of arsine on $\mathrm{Si}(001)$, revealing significant differences to phosphine. We explain how these differences result in enhanced surface immobilization and in-plane confinement of arsenic compared to phosphorus, and a dose-rate independent arsenic saturation density of $0.24 \pm \mathbf{0 . 0 4}$ monolayers. We demonstrate the successful encapsulation of arsenic delta-layers using silicon molecular beam epitaxy, and find electrical characteristics that are competitive with equivalent structures fabricated with phosphorus. Arsenic delta-layers are also found to offer confinement as good as similarly prepared phosphorus layers, while still retaining $>80 \%$ carrier activation and sheet resistances of $<2 \mathrm{k} \Omega /$ square. These excellent characteristics of arsenic represent opportunities to enhance existing capabilities of atomic-scale fabrication of dopant structures in silicon, and may be important for three-dimensional devices, where vertical control of the position of device components is critical.

KEYWORDS: scanning tunneling microscopy, density functional theory, atomic fabrication, silicon (001), arsenic, arsine, dopant

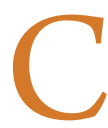

hallenges associated with the continued miniaturization of electronic devices toward the atomic-scale limit, ${ }^{1}$ and proposals for atomic-scale device architectures, e.g., to enable quantum information processing, ${ }^{2}$ have stimulated renewed interest in the investigation of dopant species in silicon. Of particular interest are methods for controlling the placement of dopant atoms in silicon with atomic-scale precision, ${ }^{3,4}$ and understanding the electronic ${ }^{5-9}$ and optical ${ }^{10-12}$ properties of single-atom and few-atom clusters of dopants. The atomic-scale control of dopant atoms in silicon using scanning tunneling microscopy (STM) has to date focused on phosphorus donors, which can be introduced into the silicon matrix using the precursor gas, phosphine $\left(\mathrm{PH}_{3}\right)$. The chemical reaction of phosphine with the silicon (001) surface has been extensively researched and is now understood in exquisite detail. ${ }^{13}$ This chemical process can be spatially controlled at the atomic scale via the use of
STM hydrogen-desorption lithography ${ }^{14}$ to produce atomically defined patterns of phosphorus donors in silicon. ${ }^{15}$ This has led to numerous exciting advances in our understanding of silicon-based electronic devices at the atomic scale, ${ }^{16-19}$ and is a promising avenue for the use of individual donor spins as qubits in a solid state quantum computer. ${ }^{20-22}$

Arsenic donors in silicon are particularly interesting, since they have a lower diffusivity and a higher solid solubility in bulk silicon than phosphorus, ${ }^{23}$ as well as a higher ionization

Received: November 11, 2019

Accepted: March 6, 2020

Published: March 6, 2020 

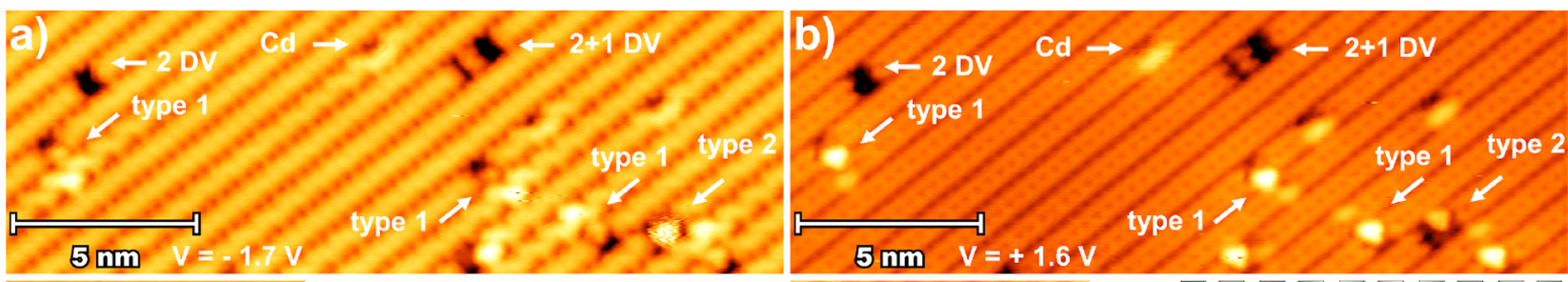

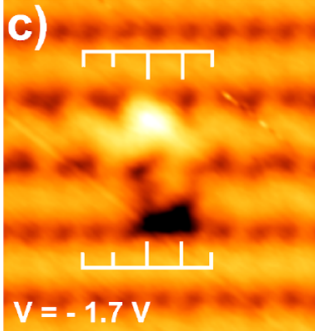

g)

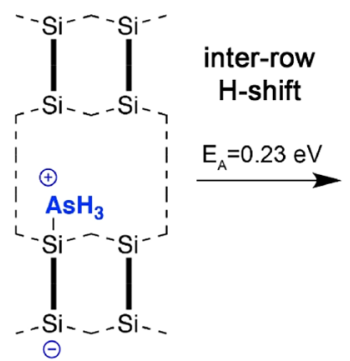

dative adsorbate

$(-0.52 \mathrm{eV})$

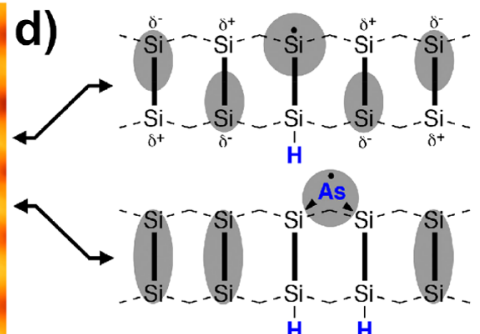

ii)

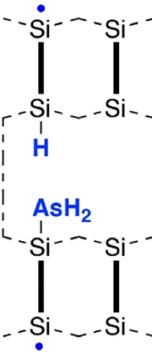

inter-row

$\mathrm{AsH}+\mathrm{H}$

$(-1.85 \mathrm{eV})$

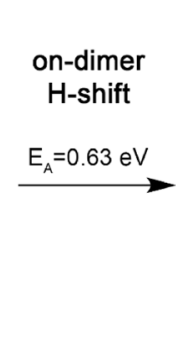

H

dimer-end

$\mathrm{AsH}+2 \mathrm{H}$

$(-2.20 \mathrm{eV})$

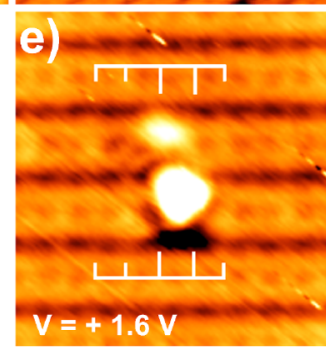

iii)

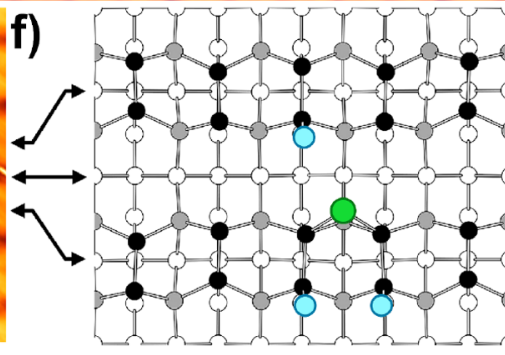

iv)

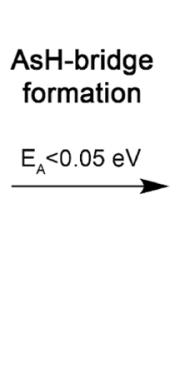

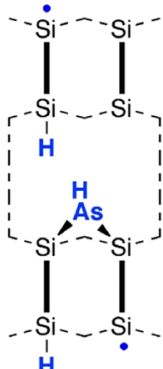

end-bridge

$\mathrm{AsH}+2 \mathrm{H}$

$(-2.62 \mathrm{eV})$

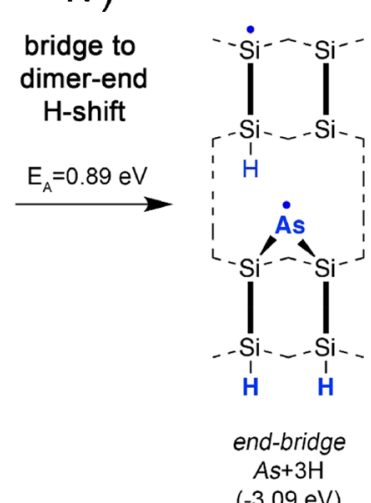

(-3.09 eV)

Figure 1. Adsorption and dissociation of single $\mathrm{AsH}_{3}$ molecules on $\mathrm{Si}(001) 2 \times 1$. (a,b) Filled and empty state $\mathrm{STM}$ images of low-coverage $\mathrm{AsH}_{3}$ on $\mathrm{Si}(001) . \mathrm{AsH}_{3}$ features are labeled type-1 and type-2, native surface defects are dimer vacancies (DV), double dimer vacancy (2DV), $2+1$ dimer vacancy complex $(2+1 \mathrm{DV})$, and C-defect $(\mathrm{Cd})$. Sample voltage, $V=-1.7 \mathrm{~V},+1.6 \mathrm{~V}$; tunneling current, $I=0.10 \mathrm{nA}$. (c) Filledstate STM image of a type-1 feature. Reticle highlights alignment with $S i$ dimers. $V=-1.7 \mathrm{~V}, I=0.10 \mathrm{nA}$. (d) Schematic valence diagram details the inter-row end-bridge As $+3 \mathrm{H}$ structure of the type-1 feature. Gray shading indicates regions imaging bright in STM. (e) Emptystate STM image of a type-1 feature. Reticles indicate the positions of $S i$ dimers. $V=+1.6 \mathrm{~V}, I=0.10 \mathrm{nA}$. (f) Structural schematic of interrow end-bridge As $+3 \mathrm{H}$ structure showing the positions of first and second layer silicon atoms (black and gray, respectively), and the single As (green) and three $\mathrm{H}$ atoms (blue) provided by the $\mathrm{AsH}_{3}$ molecule. (g) Five-step reaction path from molecularly adsorbed $\mathrm{AsH}_{3}$ to the fully dissociated inter-row end-bridge As $+3 \mathrm{H}$ structure. Calculated adsorption energies are provided in brackets for each sequential structure. Calculated activation energies, $E_{A}$, for each step are given above the reaction arrows. The STM images are skewed to account for thermal drift and rotated $\sim 45^{\circ}$ from the scan direction such that the dimer-rows align with the horizontal.

energy in silicon (53.76 meV, compared to $45.59 \mathrm{meV}$ for phosphorus), ${ }^{24}$ a larger atomic radius $\left(r_{\mathrm{As}}=115 \mathrm{pm}, r_{\mathrm{P}}=100\right.$ $\mathrm{pm}),{ }^{25}$ larger atomic spin-orbit interaction $\left(Z_{\mathrm{As}}=33, Z_{\mathrm{P}}=\right.$ $15)$, and a higher nuclear spin value $\left(I_{\mathrm{As}}=3 / 2, I_{\mathrm{P}}=1 / 2\right)$ than phosphorus. These differing properties present opportunities for atomic-scale device designs with advanced functionality, including quantum computation schemes based on silicon photonic crystal cavities, which would exploit the larger spinorbit interaction of arsenic, ${ }^{26}$ and schemes employing qudits (generalized $d$-dimensional quantum information units) where the 4-state Zeeman splitting of the arsenic 3/2 nuclear spin could be utilized as a $d=4$ qudit. ${ }^{27,28}$ In this latter case, while arsenic nuclear spins can in principle also be operated as 2state qubits with some added complexities, ${ }^{29}$ accessing the higher dimensionality provided by the $3 / 2$ spin could offer advantages over qubit based quantum computation, including simplifications in physical implementations of quantum gate structures, ${ }^{30}$ and greater efficiency and breadth of quantum simulations. ${ }^{31}$ Furthermore, the ability to position multiple dopant species in silicon with atomic-scale precision should allow independent addressing of each donor species by exploiting the different orbital excitation energies, and could thus enable principles of device operation such as optically driven silicon-based quantum gates. ${ }^{32}$ Thus, the ability to control the reaction of arsine $\left(\mathrm{AsH}_{3}\right)$ with $\mathrm{Si}(001)$ using STM hydrogen-desorption lithography, in an analogous manner to phosphine, presents enormously exciting opportunities for atomic-scale electronics.

Kipp et $a l^{33}$ have studied the adsorption of arsine on $\mathrm{Si}(001)$ using STM and X-ray photoemission spectroscopy and suggest that $\mathrm{AsH}_{3}$, adsorbed at room temperature, decomposes into $\mathrm{AsH}+2 \mathrm{H}$ and saturates at an As concentration of $\sim 20 \%$ of a silicon monolayer (ML). Several other reports on the surface chemistry and growth kinetics of arsenic layers on $\mathrm{Si}(001)$ from a gas phase arsine precursor $^{34-38}$ have been primarily concerned with rapid growth rates and elevated growth temperatures $\left(>600{ }^{\circ} \mathrm{C}\right)$, which are not compatible with the thermal requirements of STM hydrogen-desorption 
lithography. ${ }^{39,40}$ In general, however, these reports have established that arsine gas phase dosing of $\mathrm{Si}(001)$ is selflimiting at an arsenic coverage of $\sim 0.25-1 \mathrm{ML}$, dependent on the growth temperature, and therefore on the degree of $\mathrm{H}_{2}$ desorption. Previous density functional theory (DFT) studies have considered likely dissociation configurations of $\mathrm{AsH}_{3}{ }^{41}$ kinetic activation barriers for the removal of the first $\mathrm{H}$ atom, ${ }^{42}$ and comparative thermodynamic stabilities of dissociated $\mathrm{AsH}_{3}$ and $\mathrm{PH}_{3}$.

Here, we present a combined atomic-scale STM and DFT investigation of the adsorption and thermal decomposition of arsine on $\mathrm{Si}(001)$. We establish the full chemical pathway of arsine decomposition and incorporation of arsenic into the $\mathrm{Si}(001)$ surface, and also the spatial control of this reaction via STM hydrogen-desorption lithography. In particular, we demonstrate the following: (1) Individual $\mathrm{AsH}_{3}$ molecules rapidly and fully dissociate on $\mathrm{Si}(001)$ at room temperature. (2) Arsenic atoms from dissociated $\mathrm{AsH}_{3}$ molecules incorporate substitutionally into the silicon lattice at temperatures below $350{ }^{\circ} \mathrm{C}$, and at all surface coverages. (3) Arsine adsorption on $\mathrm{Si}(001)$, at room temperature, is self-terminating at a saturation coverage of $0.24 \pm 0.04$ molecules/surface silicon atom, independent of gas exposure rate, providing an arsenic coverage well above the metal-insulator transition, allowing for STM fabrication of metallic interconnects. (4) $\mathrm{AsH}_{3}$ molecules selectively adsorb and dissociate in a STM depassivated region of the $\mathrm{Si}(001)-\mathrm{H}$ surface, while leaving the surrounding $\mathrm{H}$-resist intact; subsequent annealing incorporates the arsenic atoms into the top layer of the silicon surface, without disturbing the H-resist. (5) Arsenic delta-doped layers can be grown by confining the arsenic incorporated surface below an epitaxial silicon capping layer, grown via temperatureprogrammed, low temperature epitaxy. (6) Ohmic contacts can be made to the buried, and electrically activated, arsenic-doped layer by aluminum deposition. Fulfillment of these six criteria satisfies the necessary requirements for successful STM fabrication of atomic-scale, electrically contacted, arsenic in silicon electronic devices. While very recent progress has been made using STM patterning of boron in silicon, ${ }^{44}$ the present work represents the development of the capability to pattern a dopant species, other than phosphorus, in silicon, at the atomic scale, using hydrogen-desorption lithography. Moreover, this work represents a first step in the development of a materials toolbox, where atomic-scale structures can be constructed using multiple dopant elements: an important step closer toward the emerging field of atomic-scale fabrication and manufacturing.

\section{RESULTS AND DISCUSSION}

Dissociation of Isolated $\mathrm{AsH}_{3}$ Molecules. To ascertain the atomic-scale behavior of the $\mathrm{AsH}_{3} / \mathrm{Si}(001)$ adsorption system, we exposed atomically clean $\mathrm{Si}(001) 2 \times 1$ to a low dose of arsine $\left(0.015 \mathrm{~L}\right.$ at $\left.5 \times 10^{-11} \mathrm{mbar}\right)$ at room temperature. An example of the surface observed by STM, immediately after dosing, is shown in the filled and empty-state STM images of Figure $1 \mathrm{a}$ and $\mathrm{b}$. Of the features observed, several are readily identified as native $\mathrm{Si}(001)$ surface defects, ${ }^{45}$ such as dimer vacancies (labeled DV in Figure $1 \mathrm{a}$ and $\mathrm{b}$ ) and C-defects (labeled Cd). ${ }^{46}$ The new features in these images are attributed to the products of $\mathrm{AsH}_{3}$ dissociation reacting with the surface. These are labeled "type-1" and "type-2". The type1 features are by far the most common, accounting for more than $75 \%$ of all $\mathrm{AsH}_{3}$-associated features detected at these coverages, and these are the principal focus here. The minority type- 2 features arise due to steric effects, which we briefly discuss below.

High-resolution, filled- and empty-state images of the type-1 feature are shown in Figure 1c and e, respectively. The type-1 feature is characterized by two bright protrusions on two adjacent dimer rows. These protrusions appear in both filled and empty states, but differ in their relative brightness. Across the dimer rows, i.e., along the vertical axis of the images in Figure $1 \mathrm{c}$ and $\mathrm{e}$, both protrusions are shifted up from the dimer centers, toward an upper dimer end. The short vertical lines of the overlaid white reticles on the STM images indicate the silicon dimer center positions in the horizontal direction. By reference to these reticles, we see that the upper row protrusion aligns with the third vertical line in from the left, and is thus positioned on top of a single dimer end, while the lower-row protrusion is located between the third and fourth vertical lines, and thus is positioned between two dimer ends. The upper protrusion induces strong dimer pinning, which is apparent in the filled state image (Figure 1c) as the characteristic zigzag appearance along the row.

We assign the type-1 STM feature to the structure shown in Figure $1 \mathrm{~d}$, which we call the inter-row end-bridge $\mathrm{As}+3 \mathrm{H}$ configuration. Gray highlighting in the schematic indicates sites that appear bright in the corresponding filled-state image. These bright sites correspond to the bare $\mathrm{Si}-\mathrm{Si}$ dimers that surround the adsorbate, and to the two prominent protrusions of the type- 1 feature. The two protrusions in the STM images are assigned to the dangling bond end of a $\mathrm{Si}-\mathrm{Si}-\mathrm{H}$ hemihydride dimer on the upper row, and a dimer end-bridge arsenic atom on the lower row (where the remaining two hydrogen atoms are attached to the lower row, directly across from the end-bridge arsenic atom). These two sites are both characterized by a single unpaired electron, i.e., there are halffilled molecular orbitals at these sites that would nominally image brightly in both filled and empty state. The two dimer ends opposite the bridging arsenic atom appear dark in both the filled and empty state image, which is consistent with the electronically saturated, hydrogen-termination at these sites.

Figure $1 \mathrm{~g}$ shows the proposed reaction pathway giving rise to the inter-row end-bridge $\mathrm{As}+3 \mathrm{H}$ configuration observed as the type- 1 feature. This kinetically preferred pathway is based on DFT calculations of adsorption energies of the various intermediate structures involved and the activation energies for each step along the path. Each successive step leads to a structure of lower energy, providing the thermodynamic driving force toward the final formation of the inter-row endbridge As $+3 \mathrm{H}$ configuration. The first reaction step, labeled (i) in Figure $1 \mathrm{~g}$, is the dissociation of a datively adsorbed $\mathrm{AsH}_{3}$ molecule into an $\mathrm{AsH}_{2}+\mathrm{H}$ species by means of an inter-row hydrogen shift. This reaction transfers one hydrogen atom to the adjacent dimer row, producing a hemihydride dimer. The calculated activation barrier for this reaction step is only 0.23 $\mathrm{eV}$, which corresponds to a reaction that is completed on a time scale of nanoseconds at room temperature. We note that the inter-row hydrogen shift is kinetically preferable to the alternative, (and perhaps more intuitive) on-dimer and interdimer hydrogen shifts (not shown in Figure 1g), which have calculated activation energies of 0.53 and $0.29 \mathrm{eV}$, respectively. The fact that the inter-row $\mathrm{H}$-shift is preferred, correlates well with the fact that the type-1 STM feature, contains a hemihydride on an adjacent row, and that a majority of adsorbed $\mathrm{AsH}_{3}$ molecules dissociate by this route. 
The second reaction step, labeled (ii) in Figure 1g, is also a hydrogen-shift reaction, which preferentially occurs in the ondimer direction to produce a structure that we refer to as the dimer-end $\mathrm{AsH}+2 \mathrm{H}$ structure. The calculated activation energy for this reaction is $0.63 \mathrm{eV}$, corresponding to a reaction time scale of milliseconds at room temperature. The alternative reaction, in which the hydrogen atom shifts in the interdimer direction (not shown in Figure 1g), has a slightly larger activation barrier of $0.72 \mathrm{eV}$, and is thus kinetically disfavored. The dimer-end $\mathrm{AsH}+2 \mathrm{H}$ configuration containing a singlevalent AsH fragment is a highly transient intermediate corresponding to an extremely shallow minimum on the potential energy surface. This species near-instantly stabilizes into the end-bridge $\mathrm{AsH}+2 \mathrm{H}$ species, in which the AsH fragment bridges between two dimer-ends, labeled (iii) in Figure 1g.

The final reaction step, labeled (iv) in Figure 1g, transfers a hydrogen atom from the AsH fragment to the silicon dangling bond at the opposite dimer end. This reaction produces the inter-row end-bridge $\mathrm{As}+3 \mathrm{H}$ structure that corresponds to the type-1 STM feature. The reaction barrier for this final hydrogen-shift is calculated to be $0.89 \mathrm{eV}$; this is the ratedetermining activation energy along the full dissociation path. This barrier is still low enough such that full dissociation of an adsorbing $\mathrm{AsH}_{3}$ molecule into inter-row end-bridge $\mathrm{As}+3 \mathrm{H}$ will be completed on a time scale of tens of seconds. Overall, the calculated reaction pathway is thus highly consistent with observation of the type-1 STM feature as the majority species following $\mathrm{AsH}_{3}$ chemisorption on $\mathrm{Si}(001)$.

Despite the kinetic preference for this dissociation pathway, STM images also reveal small numbers of a few alternative dissociation structures, e.g., the type- 2 feature seen in Figure la,b. These arrangements, which are kinetically disfavored on the bare $\mathrm{Si}(001)$ surface, are thought to result from steric hindrance provided by neighboring $\mathrm{AsH}_{3}$ adsorbates, or native $\mathrm{Si}(001)$ defects. A single example of the type- 2 feature is shown in Figure 1, in the bottom right of panels a and b, and notably occurs immediately adjacent a type- 1 feature. At this low coverage, the type- 2 feature comprises roughly $10-15 \%$ of the total $\mathrm{AsH}_{3}$ associated STM features, and corresponds to the intrarow end bridge structure, known to be the preferred dissociation configuration for $\mathrm{PH}_{3} / \mathrm{Si}(001) .{ }^{13}$

It is instructive here to briefly compare the dissociation of $\mathrm{AsH}_{3}$ on silicon to the analogous $\mathrm{PH}_{3} / \mathrm{Si}(001)$ system. The primary $\mathrm{PH}_{3}$ dissociation process at low coverage is a progressive sequence of three principal species, namely, $\mathrm{PH}_{2}$ $+\mathrm{H}, \mathrm{PH}+2 \mathrm{H}$, and $\mathrm{P}+3 \mathrm{H} .{ }^{47}$ Transitions along this sequence occur on a time scale of minutes, making these transitions directly observable in room-temperature STM experiments (see, e.g., Figure 6 in ref 47). In contrast, full $\mathrm{AsH}_{3}$ dissociation into the As $+3 \mathrm{H}$ species is complete before the surface can be imaged by STM after arsine exposure, leaving the type-1 STM feature as the single dominant species at low coverage. Comparison of our DFT calculations for $\mathrm{AsH}_{3} / \mathrm{Si}(001)$ with those reported for phosphine ${ }^{13}$ provides some insights into how these differences arise. First, hydrogen-shift reactions in the arsine pathway are more exothermic and have lower activation energies than the corresponding reaction in the phosphine pathway. This results in a much faster rate of dissociation for $\mathrm{AsH}_{3}$. Second, a characteristic of the phosphine pathway is that hydrogen-shift dissociation and $\mathrm{PH}_{2-}$-fragment diffusion are in close competition; this becomes manifest in the great diversity of $\mathrm{PH}_{3}$ dissociation species formed, ${ }^{43}$ and in the observed diffusion of the $\mathrm{P}$ atom away from the initial adsorption site. ${ }^{13}$ This competition no longer exists for arsine due to the much reduced hydrogen-shift activation barrier. In effect, an adsorbing $\mathrm{AsH}_{3}$ molecule rapidly falls apart where it lands, undergoing minimal rearrangement of the fragments. The result is that the arsenic atom does not have opportunity to diffuse away from the initial landing site and a single structure, namely, the inter-row end-bridge As $+3 \mathrm{H}$ structure, is formed as the majority species.

Substitutional Incorporation of Arsenic Atoms into the Silicon Lattice. Following molecular dissociation of $\mathrm{AsH}_{3}$ on the $\mathrm{Si}(001)$ surface, the next step critical to the STM lithography fabrication process, is incorporation of the arsenic atoms into the silicon lattice. Figure $2 \mathrm{a}$ and $\mathrm{b}$ show a clean $\mathrm{Si}(001)$ surface exposed to a low dose $(0.015 \mathrm{~L})$ of arsine at room temperature (Figure 2a), and then subsequently annealed to promote the incorporation of the arsenic atoms into the surface (Figure 2b). Before annealing, the surface exhibits many As $+3 \mathrm{H}$ features (type-1), two of which have been highlighted by arrows. High-resolution filled- and emptystate images of the same surface (inset to Figure $2 \mathrm{a}$ ) provide a close view of a type-1 feature (arrow) and a nearby C-defect. Figure $2 \mathrm{~b}$ shows the same surface (but a different area) after a $1 \mathrm{~min}$ thermal anneal at $500{ }^{\circ} \mathrm{C}$. Arrows in Figure $2 \mathrm{~b}$ highlight examples that, by their appearance and by analogy to the behavior of $\mathrm{PH}_{3}$ on $\mathrm{Si}(001),{ }^{48}$ we assign to $\mathrm{Si}-\mathrm{As}$ heterodimers formed during the anneal. High-resolution filled and empty state images of two such As-Si heterodimers (inset of Figure $2 \mathrm{~b}$ ) reveal an appearance that is very similar to that of $\mathrm{P}-\mathrm{Si}$ heterodimers, confirming that arsenic incorporation into the surface has taken place.

At the temperature of $500{ }^{\circ} \mathrm{C}$ used in the annealing experiment above, all hydrogen atoms are expected to desorb from the silicon surface, and thus Figure $2 \mathrm{~b}$ shows a surface completely depleted of hydrogen. At this temperature, the substituted silicon atoms, which are ejected from the surface as the As-Si dimers are formed, rapidly diffuse away from the ejection site and are eventually captured at the existing step edges, or newly formed ad-dimer rows. ${ }^{49}$ This process of controllably substituting arsenic atoms into the silicon lattice is a requirement for compatibility of arsine and arsenic with STM hydrogen resist lithography, as substitution of isolated dopant atoms is necessary if the dopants are to be activated as electron donors in STM fabricated electronic devices.

Saturation Arsine Coverage. Having resolved the elementary $\mathrm{AsH}_{3}$ single-molecule processes and arsenic surface incorporation in the low-coverage regime, we now move on to the saturation-coverage regime. High-density regions of arsenic dopants are important for STM lithography device fabrication, as these conductive $2 \mathrm{D}$ areas serve as device interconnects and contacts. Figure $2 \mathrm{~d}$ shows a large-scale STM image of the $\mathrm{Si}(001)$ surface dosed to saturation by $1.5 \mathrm{~L}$ of arsine. The image shows a disordered pattern of protrusions and depressions as expected for a surface densely covered with the products of $\mathrm{AsH}_{3}$ dissociation.

Hydrogen atoms bonded to $\mathrm{Si}(001)$ are immobile at room temperature, and in the stable configuration of the inter-row end-bridge As $+3 \mathrm{H}$ structure, the arsenic atom is locked into place by the three hydrogen atoms surrounding it. Activation barrier considerations reveal that arsenic incorporation can only take place when the thermal conditions are such that hydrogen atoms can diffuse away from the arsenic atom. The result of annealing the arsine saturated surface to $350{ }^{\circ} \mathrm{C}$ for 5 


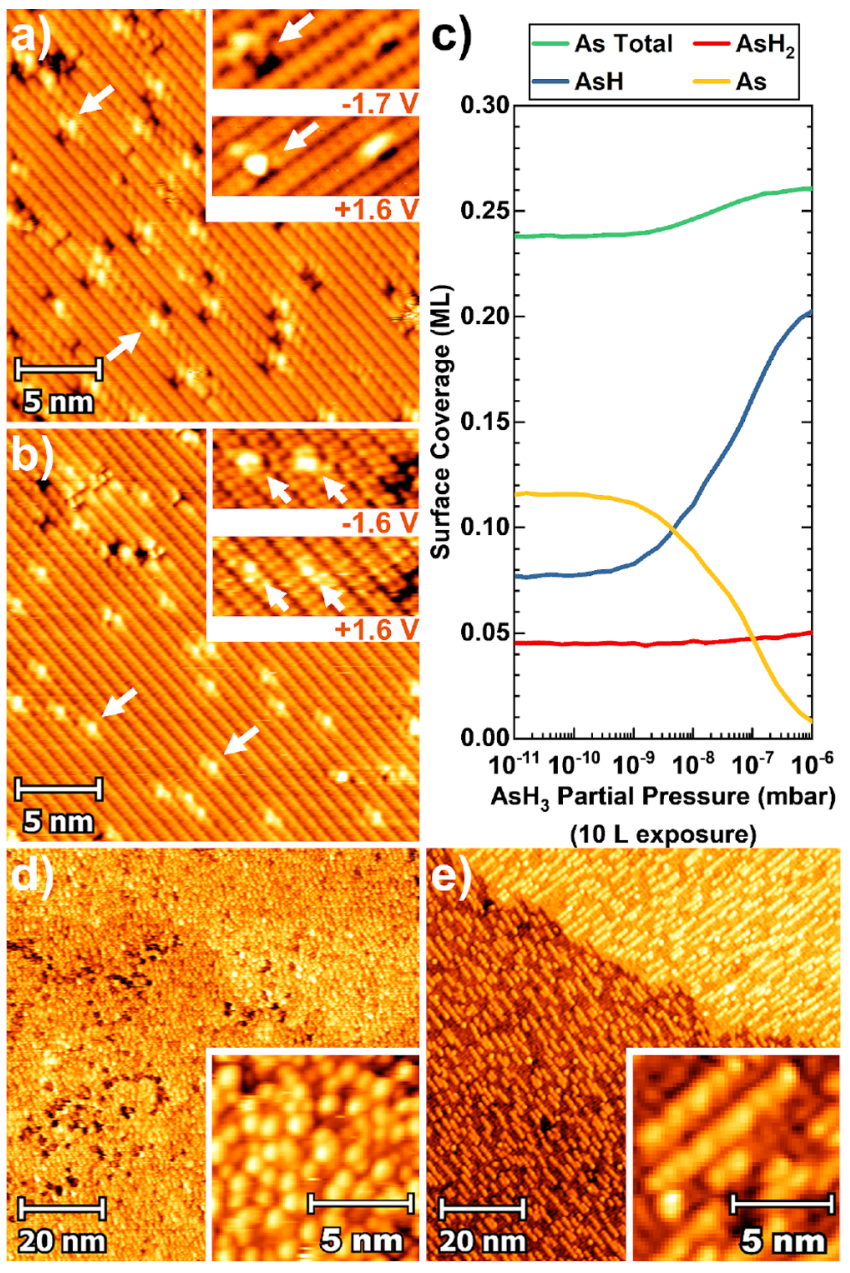

Figure 2. Substitutional incorporation of isolated arsenic atoms into the silicon lattice and saturation arsine coverage. (a) STM image of low coverage $\left(0.02\right.$ adsorbates $\left./ \mathrm{nm}^{2}\right)$, room temperature $\mathrm{AsH}_{3}$ on $\mathrm{Si}(001)$. Arrows indicate examples of isolated type-1 $\mathrm{AsH}_{3}$ features. $V=-1.7 \mathrm{~V}, I=0.02 \mathrm{nA}$. The inset shows filled and empty state images of the type-1 feature alongside a C-defect for comparison. (b) Surface from panel (a) subsequent to a $500{ }^{\circ} \mathrm{C} \times$ 1 min anneal. Isolated As-Si heterodimers (HD) are observed in the first layer of the silicon surface; examples are indicated by white arrows. $V=-1.6 \mathrm{~V}, I=0.10 \mathrm{nA}$. Two examples of the As-Si $\mathrm{HD}$ are shown in filled and empty states in the inset. (c) Kinetic Monte Carlo simulation of total As surface coverage and $\mathrm{AsH}_{x}$ species distribution, as a function of arsine partial pressure. (d) STM image of a $\mathrm{Si}(001)$ surface following a $1.5 \mathrm{~L}\left(5 \times 10^{-9} \mathrm{mbar}\right.$ $\times 5 \mathrm{~min})$ room temperature, arsine exposure. Inset shows a magnified image of the same surface. $V=-2.0 \mathrm{~V}, I=0.04 \mathrm{nA}$. (e) Surface from panel (a) subsequent to a $350{ }^{\circ} \mathrm{C} \times 1 \mathrm{~min}$ anneal. Inset shows ejected silicon dimer chains indicative of arsenic incorporation. $V=-2.0 \mathrm{~V}, I=0.05 \mathrm{nA}$.

min is shown in the STM images in Figure 2e. That incorporation has occurred is evidenced in Figure 2e by the bright linear protrusions running perpendicular to the underlying dimer rows (also see inset to Figure $2 \mathrm{~b}$ ). These bright linear protrusions correspond to short ad-dimer chains, formed from the silicon atoms ejected during arsenic incorporation. These ad-dimer chains are a familiar sight from phosphorus incorporation experiments in the context of $\mathrm{PH}_{3}$ lithographic fabrication. ${ }^{3,49}$ Because there is one ejected silicon atom for every incorporated arsenic atom, one can interpret the density of ejected silicon atoms observed in STM images as a direct measure of the density of incorporated arsenic. Using this approach we estimate the incorporated arsenic coverage in samples prepared by a saturation arsine dose of $1.5 \mathrm{~L}$ and thermal anneal of $350{ }^{\circ} \mathrm{C}$ to be $0.24 \pm 0.04$ ML.

We find that this incorporated arsenic coverage is independent of the arsine saturation dose rate, which is interesting since this is not the case for phosphine (discussed further below). Saturation dosing at different rates can be achieved by changing the arsine partial pressure, with simultaneous adjustment of the total exposure time. When the arsine dose rate is varied by decreasing the arsine partial pressure from $5 \times 10^{-9} \mathrm{mbar}$ to $5 \times 10^{-10} \mathrm{mbar}$ (along with a dose equalizing change in total exposure time from 5 to 50 min), the resulting total arsenic coverage is found to be constant within measurement error. This dose-rate independent saturation arsenic coverage can be explained as follows. (i) At low coverages $\left(\lesssim 2 \times 10^{12}\right.$ molecule $\left./ \mathrm{cm}^{2}\right)$, $\mathrm{AsH}_{3}$ moieties dissociate rapidly $(\sim 10 \mathrm{~s})$ and completely at random locations. (ii) As the density of surface adsorbates increases, the occupied sites begin to sterically hinder the complete dissociation of further incoming $\mathrm{AsH}_{3}$, resulting in the subsequent adsorption of a distribution of partially dissociated $\mathrm{AsH}_{x}$ moieties-a distribution determined by site availability, not dissociation rate. (iii) Eventually all adsorption sites are blocked and coverage becomes saturated, leaving a final surface comprised of all possible $\mathrm{AsH}_{x}$ moieties.

The constant incorporated arsenic coverage value, measured across a range of arsine dose rates, is also found to be consistent with predictions from simple kinetic Monte Carlo (KMC) simulations that utilize activation energies from our DFT-derived dissociation pathway (Figure $1 \mathrm{~g}$ ). The results of these simulations are plotted in Figure 2c. Here, we use KMC calculations to determine the total arsenic coverage at saturation, for a range of arsine partial pressures, spanning five orders of pressure magnitude, in which the distribution of $\mathrm{AsH}_{x}$ fragments is allowed to vary. We assume that isolated molecules will dissociate in the type-1 structure, with a 2.5 dimer footprint discussed in the Dissociation of Isolated $\mathrm{AsH}_{3}$ Molecules section, but that as the surface fills in, and silicon site availability becomes reduced, $\mathrm{AsH}_{3}$ dissociation will be halted at different stages leaving behind $\mathrm{AsH}$ and $\mathrm{AsH}_{2}$ fragments. Although the ratio of $\mathrm{As}, \mathrm{AsH}$, and $\mathrm{AsH}_{2}$ varies as a function of partial pressure, the total number of arsenic atoms present on the surface remains in the 0.24-0.26 ML range, and the arsenic surface concentration only increases by $2-3 \%$ as the dose rate is increased across the full range.

This dose rate independence of arsenic coverage in the saturated $\mathrm{AsH}_{3} / \mathrm{Si}(001)$ system is in direct contrast to the $\mathrm{PH}_{3} / \mathrm{Si}(001)$ system, where phosphorus coverage at saturation is found to be dose-rate dependent at room temperature. ${ }^{50-52}$ When $\mathrm{Si}(001)$ is saturated with $\mathrm{PH}_{3}$ there is competition over available bare surface dimers between the adsorbing $\mathrm{PH}_{3}$ molecules and the dissociating $\mathrm{PH}_{2}+\mathrm{H}$ species. For $\mathrm{AsH}_{3}$, this competition no longer exists, due to a dissociation rate that is 3 orders of magnitude more rapid than that of $\mathrm{PH}_{3}$. In effect, any adsorbing $\mathrm{AsH}_{3}$ molecule breaks apart on the $\mathrm{Si}(001)$ surface to a degree limited only by the availability of bare $\mathrm{Si}$ dimer sites surrounding the molecule.

The much more rapid dissociation of $\mathrm{AsH}_{3}$ also manifests in a lack of ordering in this system. The saturated surface and magnified inset shown in Figure 2d show very little evidence of long- or short-range ordering. This is once again in direct 
contrast to the $\mathrm{PH}_{3} / \mathrm{Si}(001)$ system, where $\mathrm{PH}_{2}$ moieties are found to assemble in small patches of local $p(2 \times 2)$ ordering, with $\mathrm{PH}$ moieties aligned along $\mathrm{Si}$ dimer rows. ${ }^{50}$ In the case of $\mathrm{PH}_{3}$, dissociation and removal of successive $\mathrm{H}$ atoms from the $\mathrm{PH}_{x}$ moieties occurs on the time scale of minutes, and the moieties survive long enough to undergo diffusion from the initial adsorption site to energetically preferred, ordered sites. In the $\mathrm{AsH}_{3} / \mathrm{Si}(001)$ system, the $\mathrm{H}$ atoms are stripped from the molecule much more rapidly, with isolated molecules completely dissociating on the time scale of tens of seconds. The $\mathrm{AsH}_{x}$ moieties do not have opportunity to diffuse before fully dissociating, and at saturation coverage they remain immobilized at the initial, random landing site, producing the completely disordered surface shown in Figure 2a.

Adsorption and Incorporation of Arsenic through a Hydrogen Resist. We now demonstrate that the arsine adsorption, dissociation, saturation, and incorporation on the clean $\mathrm{Si}(001)$ surface, as described above, is compatible with hydrogen desorption lithography. For compatibility with the STM fabrication process, $\mathrm{AsH}_{3}$ molecules must selectively adsorb only on depassivated $\mathrm{Si}(001)$ regions and not on the passivated $\mathrm{Si}(001): \mathrm{H}$ surface. Furthermore, to allow for maximum in-plane confinement and fabrication flexibility, arsenic should also incorporate into the silicon lattice at anneal temperatures below the onset of $\mathrm{H}_{2}$ desorption $\left(380{ }^{\circ} \mathrm{C}\right)$. Fulfillment of both these requirements is demonstrated in Figure 3. Each panel in this figure corresponds to one step in the STM lithography patterned doping process, with the corresponding steps indicated by the inset schematics on each STM image.

In the first step, a hydrogen passivated $\mathrm{Si}(001)$ surface is prepared, as shown in Figure 3a. Each silicon atom has one or two hydrogen atoms bonded to it, except in a few cases where the hydrogen atom is missing, leaving a dangling bond (DB). The DBs have the appearance of bright dots in the image and the $\mathrm{DB}$ density is $<1 \%$. Selective removal of a region of the hydrogen "resist" layer is achieved by scanning over a $50 \times 50$ $\mathrm{nm}$ region of the surface using an increased bias/current of $+7.0 \mathrm{~V}$ and $1.0 \mathrm{nA}$, at a tip raster speed of $100 \mathrm{~nm} / \mathrm{s}$ (Figure $3 \mathrm{~b})$. The patterned region, in the center of the image, shows the density of bright dots now approaches $100 \%$ coverage of the surface, indicating that most of the hydrogen atoms have been desorbed from the surface, leaving behind the bare silicon.

Dosing the patterned surface of Figure $3 \mathrm{~b}$ with $1.5 \mathrm{~L}$ of arsine results in $\mathrm{AsH}_{x}$ moieties (where $x=0-3$ ) selectively adsorbing within the patterned area, producing a saturation arsenic density of $0.24 \mathrm{ML}$. An image of this surface is shown in Figure 3c. Following arsine dosing, the exposed region of the surface has a different appearance, consisting of a high density of features, whose identity is hard to distinguish due to their tight and disordered packing. An enlargement of the upper right corner of the patterned and dosed area is shown in Figure 3e. It is clear from these images that arsenic containing molecules from the gas phase have attached to the silicon surface where the hydrogen resist has been removed, while the resist protects the surface from $\mathrm{AsH}_{3}$ adsorption elsewhere.

In the final step, shown in Figure 3d, annealing the surface to $350{ }^{\circ} \mathrm{C}$ for $2 \mathrm{~min}$ results in substitutional incorporation of arsenic and the ejection of silicon onto the surface, exclusively within the patterned area. Additional bright spots now present in the image outside of the patterned region are silicon dangling bonds, introduced in the hydrogen mask by the

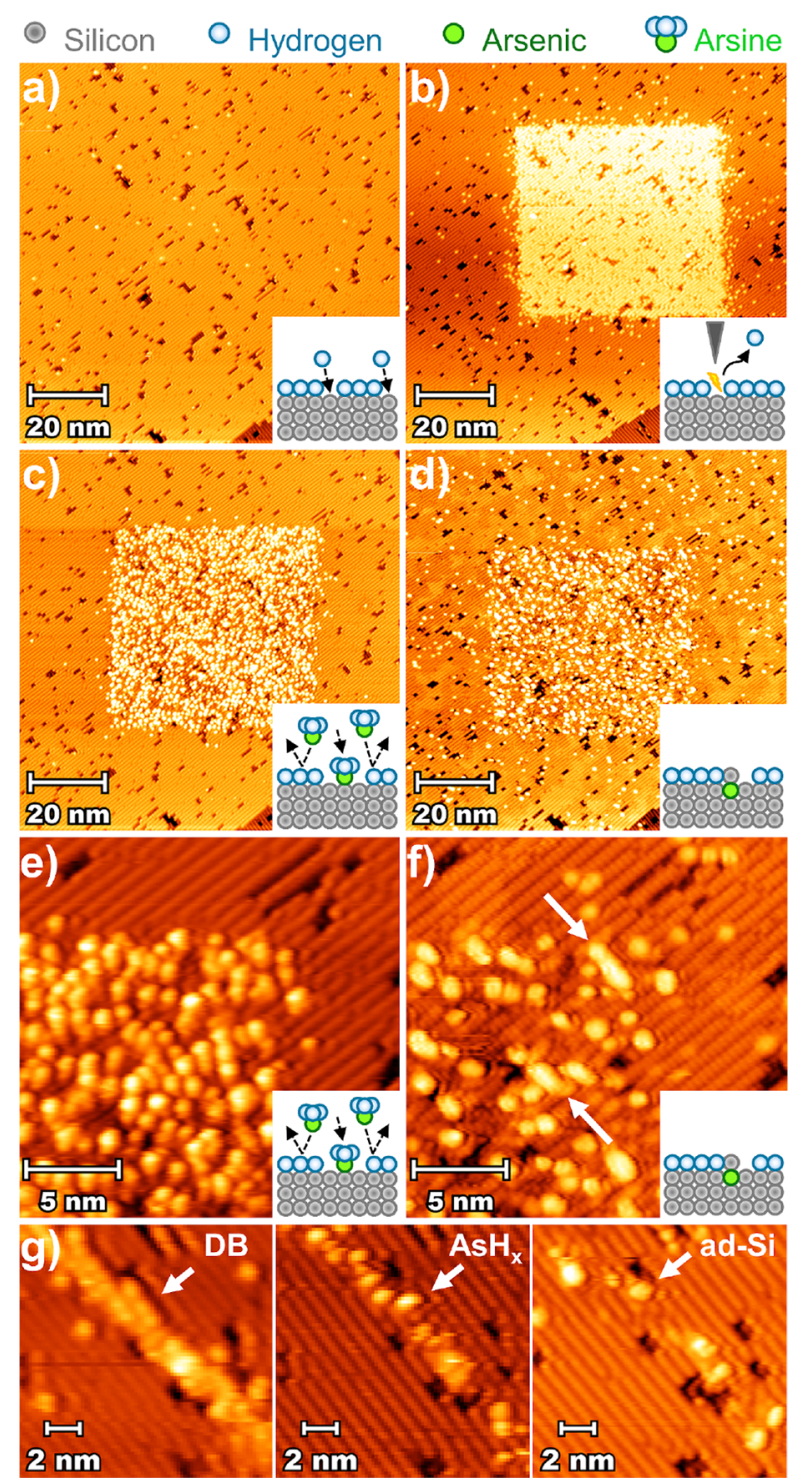

Figure 3. Compatibility of $\mathrm{AsH}_{3}$ adsorption, dissociation, and incorporation with STM hydrogen resist lithography. $(a-f)$ Sequential STM images of the same $100 \times 100 \mathrm{~nm}$ area on a $\mathrm{Si}(001)-\mathrm{H}$ surface showing that the $\mathrm{H}$-resist remains intact and free from adsorbates throughout each step of the STM lithography process. (a) Clean hydrogen terminated $\mathrm{Si}(001)$ surface prior to STM lithography or arsine exposure. (b) Selected area hydrogen desorption of a $50 \times 50 \mathrm{~nm}$ square $(V=+7.0 \mathrm{~V}, I=1 \mathrm{nA}, s=100$ $\mathrm{nm} / \mathrm{s})$. (c) $1.5 \mathrm{~L}$ arsine dose results in selective adsorption only within the lithographically defined area. (d) $350{ }^{\circ} \mathrm{C} \times 1 \mathrm{~min}$ anneal, results in incorporation of the adsorbed arsenic atoms as evidenced by presence of ejected $\mathrm{Si}$. (e) Enlargement of the upper right-hand corner of the patterned square in panel (c). The disordered saturation arsenic layer is clearly contained within only the patterned region, and there is no adsorption on the resist. (f) Enlargement of the upper right-hand corner of the patterned square in panel (d). Short $\mathrm{Si}$ dimer chains, evidence of arsenic incorporation, are indicated by the arrows. The surrounding hydrogen resist remains essentially intact with only a small density of additional dangling bonds produced by the incorporation anneal. $V=-2.0 \mathrm{~V}, I=0.10 \mathrm{nA}$. (g) Sequential images of hydrogen desorption, $\mathrm{AsH}_{3}$ adsorption, and As incorporation along a line that is only $2 \mathrm{Si}$ dimer rows wide. Arrows indicate a silicon dangling bond (DB) dimer, an adsorbed/dissociated $\mathrm{AsH}_{x}$ moiety, and finally ejected silicon (ad-Si). 

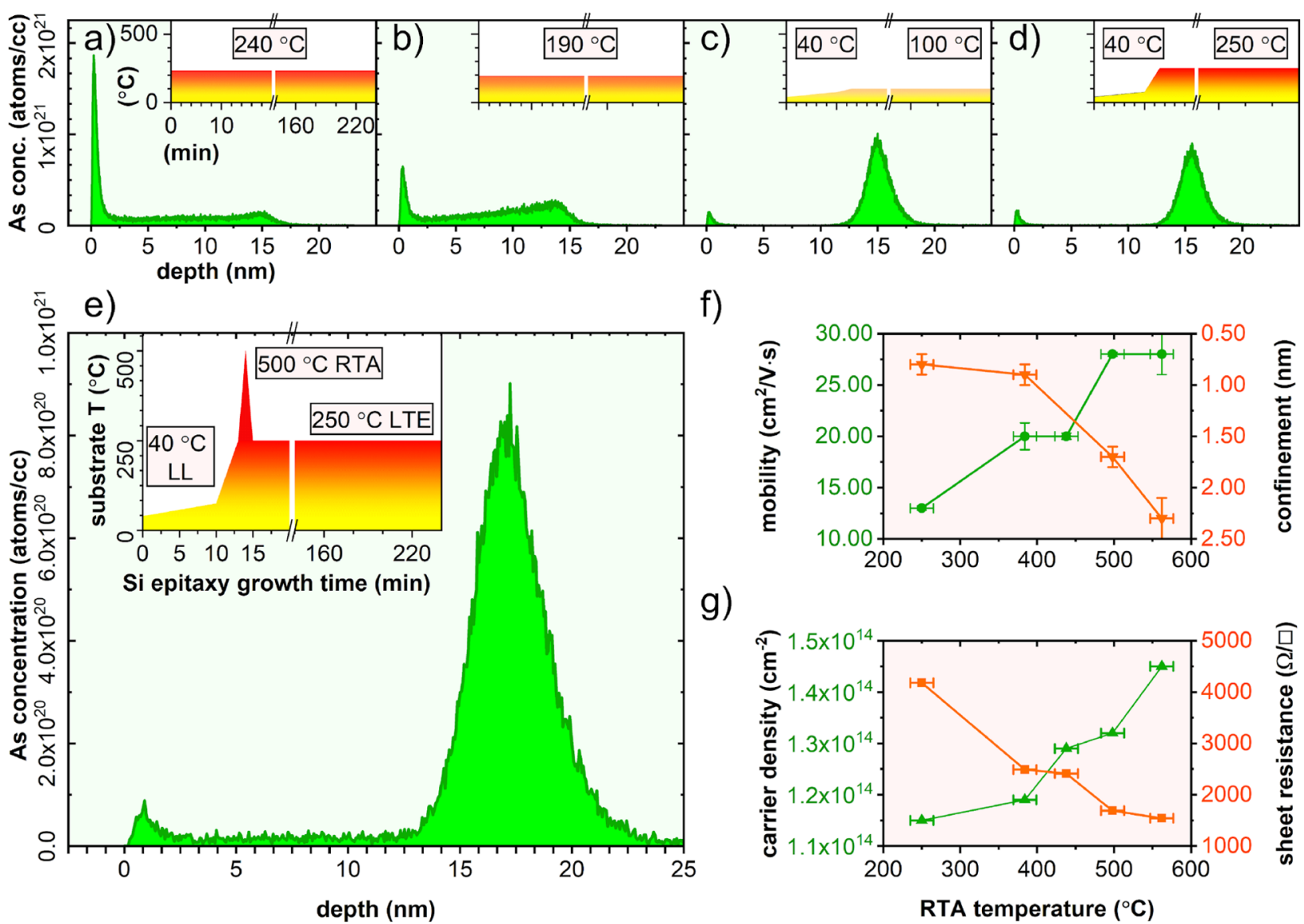

f)

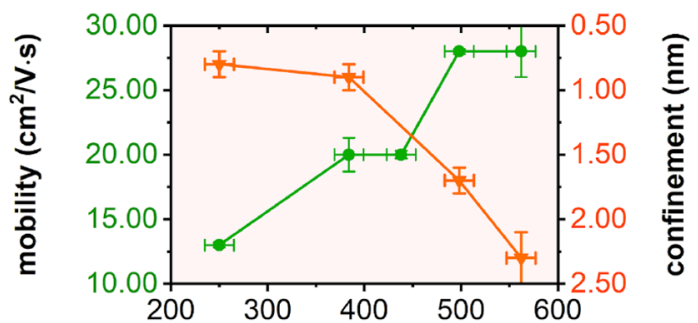

g)

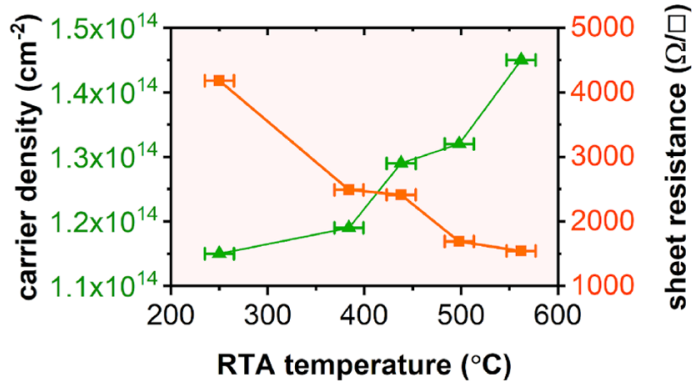

Figure 4. Arsenic $\delta$-layer distribution and electronic transport controlled through a silicon overgrowth thermal annealing program. (a-e) SIMS profiles of five different saturation arsenic $\delta$-layer samples overgrown with $15 \mathrm{~nm} \mathrm{Si}$, at a deposition rate of $1 \mathrm{ML} / \mathrm{min}$. Sample temperature program during silicon epitaxy was modified for each sample according to the inset temperature $v s$ time profiles. (f) $\delta$-Layer mobility and confinement as a function of RTA temperature. $(\mathrm{g}) \delta$-Layer carrier density and sheet resistance as a function of RTA temperature. Error bars in the plots in panels $\mathrm{f}$ and $\mathrm{g}$ account for temperature measurement uncertainty and magnetoresistance curve fitting confidence levels as explained in the Supporting Information, section b.

incorporation anneal. Once again, an enlargement of the upper right-hand corner of the patterned and dosed area (this time postanneal) is shown in Figure 3d. Two examples of short dimer chains consisting of ejected silicon atoms are highlighted with arrows. Confirmation of the successful execution of this final step demonstrates that an arsenic dopant layer can be substitutionally incorporated into an arbitrarily defined region of a silicon surface, where the shape of the region is defined by the hydrogen desorption pattern written by an STM tip.

Finally, the full patterning process is repeated on the atomic scale in Figure $3 \mathrm{~g}$. Here we demonstrate hydrogen desorption, $\mathrm{AsH}_{3}$ adsorption/dissociation, and finally As incorporation along a patterned line of exposed dangling bonds only 2 silicon dimer rows wide. Arrows in these three images highlight a silicon dangling bond (DB) dimer in the first image, an adsorbed $\mathrm{AsH}_{x}$ moiety in the second, and an ejected silicon adatom (ad-Si) adsorbed on the surface. The resulting patterned line of incorporated arsenic atoms is at most a few atoms wide.

Encapsulation of Arsenic Layers: Low Temperature Silicon Epitaxy. The final, in situ, ultrahigh vacuum step in the STM device fabrication is encapsulation with crystalline silicon. Once the arsenic atoms are incorporated into the silicon surface through a patterned hydrogen resist, the dopant structure must then be buried beneath a few nanometers of epitaxial silicon. This protective capping layer is grown via molecular beam epitaxy, using a solid intrinsic silicon sublimation source (SUSI-40, MBE Komponenten $\mathrm{GmbH}$ ).

The thermal budget of the sample during the epitaxy stage is tightly restricted by two competing requirements: (1) dopant segregation and diffusion must be minimized so that the substitutional arsenic atoms remain in position-demanding a minimization of sample temperature; and (2) crystallographic defect formation must be minimized to ensure that arsenic donor atoms remain electrically activated-usually achieved by elevated temperature overgrowth. ${ }^{53}$ In the case of phosphorus, these two requirements can be reasonably satisfied by holding the sample temperature constant at $250{ }^{\circ} \mathrm{C}$, throughout. In the case of arsenic we find (via secondary ion mass spectrometry; SIMS) that this approach is inadequate. We attribute this to the fact that arsenic is considerably more prone to surface segregation. $^{54}$ As described below, we have determined a variable sample temperature program during overgrowth that suppresses arsenic surface segregation during silicon epitaxy, allowing for the growth of both well confined and electrically activated arsenic $\delta$-layers.

To achieve thermal control of arsenic segregation and diffusion during silicon epitaxy, a number of saturation arsenic delta layers were overgrown with $15 \mathrm{~nm}$ of silicon at a rate of 1 $\mathrm{ML} / \mathrm{min}$, using different sample temperature programs. 
Arsenic concentration depth profiles were subsequently measured using SIMS, and Figure 4 shows SIMS data for four different temperature programs as described by the temperature $v s$ time insets in each SIMS profile. Figure 4a shows the result of silicon overgrowth at a constant sample temperature of $240{ }^{\circ} \mathrm{C}$. This arsenic distribution is dominated by a high and narrow peak located at a depth of $\sim 1 \mathrm{~nm}$. Beneath this narrow surface peak the arsenic concentration reduces to a much lower, but not an insignificant constant level $\left(>1 \times 10^{18}\right.$ atoms $\left./ \mathrm{cm}^{-3}\right)$ before terminating in a slight peak at the $\delta$-layer origin depth, $15 \mathrm{~nm}$ below the surface. Beyond this depth, the arsenic concentration rapidly drops below the instrument's detection limit $\left(1 \times 10^{18}\right.$ atoms $\left./ \mathrm{cm}^{3}\right)$. From this we conclude that the arsenic layer is not effectively buried beneath the silicon, but rather, a large percentage of the 0.24 $\mathrm{ML}$ of arsenic atoms undergo continual cycles of surface segregation, i.e., they exchange positions with newly arrived silicon adatoms, and assume energetically preferred positions within the top layer. ${ }^{55,56}$

Figure $4 \mathrm{~b}$ shows the arsenic profile for overgrowth at a constant but lower temperature of $190^{\circ} \mathrm{C}$. Here we observe a shift in weight from the surface to the subsurface arsenic peak, and find that the arsenic concentration is no longer uniform in the region between peaks. Below the surface peak, it slowly rises to an asymmetric peak at the arsenic origin depth of $\sim 15$ $\mathrm{nm}$, before rapidly falling off below the detection limit. Segregation is an activated process, and by lowering the constant growth temperature the segregation is found to be partially suppressed.

This arsenic segregation suppression can be further enhanced through a greater reduction in substrate temperature during encapsulation. Figure $4 \mathrm{c}$ shows the arsenic profile resulting from overgrowth at the lowest achievable sample temperature given our silicon source-sample geometry. In this case, there is no Joule heating of the sample, only the unavoidable radiative heating from the silicon MBE source. The substrate begins overgrowth at $40{ }^{\circ} \mathrm{C}$ increasing to a stable $100{ }^{\circ} \mathrm{C}$ after the first $12 \mathrm{~min}$ of growth $(12 \mathrm{ML})$. From the SIMS profile, we see that arsenic surface segregation is highly suppressed in this sample, resulting in a very well confined $(<2$ $\mathrm{nm}$ fwhm $)$ and symmetric peak $\left(\sim 5 \times 10^{20}\right.$ atoms $\left./ \mathrm{cm}^{-3}\right)$ located at the origin depth of $15 \mathrm{~nm}$. This peak, which falls rapidly to below the instrument's detection limit within $3 \mathrm{~nm}$ in either direction, represents the best achievable confinement of the arsenic $\delta$-layer grown in our MBE system. However, due to the reduced substrate temperature during overgrowth, and the high concentration of arsenic surface atoms, the critical thickness at which the epitaxial layer becomes amorphous will also be reduced considerably. ${ }^{57}$ At a temperature of 100 ${ }^{\circ} \mathrm{C}$, and deposition rate of $1 \mathrm{ML} / \mathrm{min}$, the critical thickness is expected to reduce below $2 \mathrm{~nm},{ }^{53}$ meaning the upper $13 \mathrm{~nm}$ or more of silicon will be amorphous, and unsuitable for device encapsulation.

In order to facilitate suppression of arsenic segregation during reduced temperature silicon overgrowth, yet still achieve epitaxy and avoid amorphization, we have developed the strategy (adapted from a similar concept used first for phosphorus $\delta$-layers in germanium, ${ }^{58-60}$ and later for phosphorus $\delta$-layers in silicon ${ }^{61-63}$ ) of growing a very thin, reduced temperature "locking layer" that is kept below the critical amorphization thickness. With a reduced temperature locking layer in place, the substrate is then heated to a temperature that can support epitaxial growth for the remainder of the overlayer deposition. Figure $4 \mathrm{~d}$ shows an example of locking layer assisted epitaxial growth applied to an arsenic $\delta$-layer. Here the sample is not actively heated for the first $10 \mathrm{~min}$ ( $10 \mathrm{ML}$ for a $1 \mathrm{ML} / \mathrm{min}$ growth rate) after which it is then rapidly heated to $250{ }^{\circ} \mathrm{C}$, and held constant for the remaining $230 \mathrm{~min}$ of overgrowth. Comparing the SIMS profiles of Figure $4 \mathrm{c}$ and $\mathrm{d}$, we see that increasing the temperature to $250{ }^{\circ} \mathrm{C}$ following growth of a $10 \mathrm{ML}$ locking layer, has no detrimental effect on the confinement. The locking layer strongly suppresses arsenic surface segregation, producing epitaxially capped arsenic $\delta$-layers with very tight confinements-confinements which are limited primarily by the solid-state diffusivity of arsenic in silicon. It is interesting to note here that arsenic has a lower diffusion coefficient than phosphorus in bulk silicon. ${ }^{23}$ Arsenic structures buried in silicon should therefore be less prone to pattern smearing at increased processing temperatures compared to phosphorus structures.

Electrical Activation and Contacting of Arsenic $\delta$ Layers. To establish full compatibility of arsine and arsenic with the STM device fabrication process, the buried arsenic dopant structures must be electrically activated and Ohmic contacts achieved with the arsenic layer beneath the silicon cap. Satisfaction of this requirement has been verified by measurement of linear and symmetric IV curves during standard magnetotransport characterization of the arsenic $\delta$ layers. As explained in detail in the Supporting Information, Hall bars were fabricated from locking layer encapsulated arsenic $\delta$-layers, and Ohmic contacts achieved through deposition of aluminum directly onto the $\delta$-layer edge. We note that phosphorus doped, n-type substrates (donor concentration $N_{\mathrm{D}}=5 \times 10^{14}$ to $5 \times 10^{15} \mathrm{~cm}^{-3}$ ) are used in this work. This doping level allows for direct current sample heating and room temperature STM measurements, and does not interfere with the low temperature transport measurements of the delta layers.

In addition to fabricating Ohmic contacts, we have also optimized the transport properties of the arsenic $\delta$-layers for improved device performance. The optimizations were achieved by improving the epitaxial silicon quality and minimizing crystallographic defects, resulting in a maximization of carrier density and mobility, and a minimization of sheet resistance. Despite the fact that the locking layer thickness used is below the critical amorphization limit, including this reduced temperature step in the overgrowth is detrimental to crystal quality, and thus to the electrical performance of the $\delta$-layers. To overcome this issue, we include a rapid thermal anneal (RTA) stage in the overgrowth sample temperature program, as has been done for phosphorus $\delta$-layers. ${ }^{61-63}$

Figure 4e shows the SIMS profile of an arsenic $\delta$-layer grown using both locking layer and RTA stages in the substrate temperature program. The temperature $v s$ time profile used here is shown in the inset of Figure 4e. It is similar to the profile shown in the inset of Figure $4 \mathrm{~d}$, with the exception of the additional $500{ }^{\circ} \mathrm{C} \times 10 \mathrm{~s}$ RTA, occurring between the locking layer growth and constant temperature epitaxy stages. Comparing the SIMS profiles of Figure $4 \mathrm{~d}$ and e, we find that introduction of this RTA stage is not detrimental to the enhanced confinement provided by the locking layer in any significant way. The effect of the RTA on transport properties is however significant. 
Figure $4 \mathrm{f}$ and $\mathrm{g}$ show the effect of the RTA temperature maximum on $\delta$-layer carrier concentration, sheet resistance, mobility, and confinement. The data for these figures of merit were obtained from Hall measurements on five arsenic $\delta$-layers, with heating profiles identical to that of Figure 4e, except with each using a different RTA peak value, covering the range from 250 to $560{ }^{\circ} \mathrm{C}$. For a RTA greater than $500{ }^{\circ} \mathrm{C}$, the electronic layer thickness increases beyond $2 \mathrm{~nm}$, while the improvement in sheet resistance and mobility has leveled out. For this reason, the RTA temperature maximum is considered optimum at $\sim 500{ }^{\circ} \mathrm{C}$. Despite the fact that both the mobility and sheet resistance values plateau at $28 \pm 1 \mathrm{~cm}^{2} /(\mathrm{V} \cdot \mathrm{s})$, and $1.6 \pm 0.1 \mathrm{k} \Omega /$ square, respectively, the carrier density continues increasing beyond this optimum RTA temperature. At the highest RTA temperature maximum examined, $560{ }^{\circ} \mathrm{C}$, we measure a carrier density of $1.45 \times 10^{14} \mathrm{~cm}^{-2}$, which corresponds to an arsenic donor atom density of only 0.21 ML. Given our estimate of arsenic saturation coverage at 0.24 ML, this maximum value represents an activation of $88 \%$ of the donor atoms. At the optimized RTA temperature of $500{ }^{\circ} \mathrm{C}$, this activation percentage is even lower at $81 \%$. Nevertheless, this carrier concentration is well above the metal insulator transition, and greater than $1 / 2$ of the typical carrier density of $2.4 \times 10^{14} \mathrm{~cm}^{-2}$ found in phosphorus $\delta$-layers. It is not entirely surprising that less than $100 \%$ of the arsenic $\delta$-layer donor atoms are electrically activated, even at the highest RTA temperature used, as arsenic is known to suffer from clustering at high concentrations, ${ }^{64,65}$ resulting in incomplete activation at concentrations $>10^{20} \mathrm{~cm}^{-3}$ (or $2 \times 10^{13} \mathrm{~cm}^{-2}$ ) in traditional implantation or diffusion doping of silicon. ${ }^{53}$

Given the large parameter space involved in optimizing arsenic $\delta$-layer growth for both confinement and electrical transport, there is potentially room for improvement in performance values beyond those presented here. However, comparing the figures of merit achieved for arsenic $\delta$-layers with those typically achieved for phosphorus $\delta$-layers, ${ }^{61,63}$ we find that they are at most a factor of 2 worse, and that arsine and arsenic are $100 \%$ compatible with atomic-scale STM device fabrication, and therefore represent a viable alternative to phosphine and phosphorus.

\section{CONCLUSIONS}

We have demonstrated the full compatibility of arsine as a precursor gas for the atomic-scale positioning of arsenic donors in silicon using STM-based hydrogen-desorption lithography, and, when combined with low temperature silicon epitaxy, the capability to fabricate buried, atomic-scale, dopant structures in silicon. Room temperature dissociation of arsine on $\mathrm{Si}(001)$ differs from the dissociation of phosphine on $\mathrm{Si}(001)$ in that full dissociation of arsine occurs much more rapidly at room temperature. We find also that saturation arsine coverage is self-limiting at $24 \% \mathrm{ML}$, invariant with dose rate, and that monolayer hydrogen termination acts as an effective resist layer for the adsorption of arsine on $\mathrm{Si}(001)$. We show that arsenic can be incorporated in the silicon surface lattice by annealing at $350{ }^{\circ} \mathrm{C}$. We demonstrate successful low temperature silicon epitaxial overgrowth by growing arsenic $\delta$-layers, where segregation was suppressed through the use of an unheated, ultrathin, locking layer. A rapid thermal anneal stage of $500 \mathrm{C}$ $\times 10 \mathrm{~s}$ immediately following locking layer growth improves electronic transport properties resulting in $2 \mathrm{~nm}$ thick, conductive layers with sheet resistance, and carrier concentration of $1.5 \mathrm{k} \Omega$ /square, and $1.3 \times 10^{14} \mathrm{~cm}^{-3}$, respectively. It has been a decade and a half since phosphorus dopant placement using STM H-lithography was first demonstrated, and the work presented here shows that using arsenic as the ntype dopant in place of phosphorus is possible. Finally, the parameters used for arsenic and for phosphorus device fabrication are completely compatible with one another, demonstrating the possibility of multispecies dopant devices.

\section{EXPERIMENTAL METHODS}

Sample Preparation and Scanning Tunneling Microscopy. $\mathrm{Si}(001)$ samples were diced to $2 \times 9 \mathrm{~mm}$ from a $0.3 \mathrm{~mm}$ thick, Czochralski grown, bulk phosphorus doped wafer with a resistivity of $1-10 \Omega \cdot \mathrm{cm}$. Samples were cleaned ultrasonically ex situ in acetone followed by isopropyl alcohol, then thermally outgassed in situ (base pressure $<1 \times 10^{-10} \mathrm{mbar}$ ) for $>8 \mathrm{~h}$ at $600{ }^{\circ} \mathrm{C}$, and finally flash annealed multiple times at $1200{ }^{\circ} \mathrm{C}$, using direct current resistive sample heating. Sample temperature was monitored using an infrared pyrometer (IMPAC IGA50-LO plus), with a total estimated measurement uncertainty of $\pm 30{ }^{\circ} \mathrm{C}$. Silicon epitaxy was performed at a base pressure of $1 \times 10^{-10} \mathrm{mbar}$, using an all silicon, solid sublimation source (SUSI-40, MBE Komponenten $\mathrm{GmbH}$ ) operated at a deposition rate of $1.5 \AA / \mathrm{min}$. During silicon overgrowth, sample temperature was indirectly monitoring by measuring sample resistance, while the sample was heated using direct current resistive sample heating. All scanning tunneling microscopy measurements were performed in an Omicron variable temperature series STM at room temperature with a base pressure of $<5 \times 10^{-11} \mathrm{mbar}$.

Density Functional Theory Calculations. All DFT calculations reported here were conducted using the Gaussian 09 software and methods of energy computation and geometry optimization implemented therein. ${ }^{66} \mathrm{We}$ calculate adsorption energies for various arsine configurations on the silicon (001) surface using an approach that we refer to as the cluster composite model (CCM). ${ }^{13,67}$ This approach uses the B3LYP hybrid exact-exchange density functional and a large $6-311 \mathrm{G}(2 \mathrm{df}, 2 \mathrm{pd})$ atom-centered basis set, and the $\mathrm{Si}(001)$ surface is represented using hydrogen-truncated cluster models, such as $\mathrm{Si}_{15} \mathrm{H}_{16}$ or $\mathrm{Si}_{54} \mathrm{H}_{44}$, with correction terms applied to minimize the effects of finite cluster size. The CCM approach has an established track record of describing the dissociation pathways of small molecules on the $\mathrm{Si}(001)$ surface and providing an explanation of the adsorbate species observed in STM experiments (see, e.g., refs 13, $46,68,69)$ The specific approach used here for the $\mathrm{AsH}_{3} / \mathrm{Si}(001)$ system is exactly the same as in our previous work describing the complex dissociation pathways of the analogous $\mathrm{PH}_{3} / \mathrm{Si}(001)$ system, ${ }^{13}$ and the reader is referred to this article for the full technical details. While this approach may be computationally expensive, it has been proven for the $\mathrm{PH}_{3}$ system, and its use here allows direct and transparent comparison between the two systems. Reaction step (i) in Figure $2 \mathrm{~g}$ was calculated using what is referred to as the 3D2R cluster model in ref 13 , while reaction steps (ii), (iii), and (iv) used the 2D1R cluster model with the hemihydride dimer represented by a separate cluster (see eq 5 in ref 13).

Kinetic Monte Carlo Simulations. KMC methods are explained in detail in the Supporting Information.

Secondary Ion Mass Spectrometry. Time of flight (ToF) SIMS measurements were made using an IONTOF ToF-SIMS ${ }^{5}$ system with a $25 \mathrm{keV} \mathrm{Bi}^{+}$primary ion beam in high current bunch mode (HCBM), and a $500 \mathrm{eV}, 35 \mathrm{nA} \mathrm{Cs}^{+}$sputter beam. Depth profiles were made with a $300 \mu \mathrm{m}^{2}$ sputter crater, and the analytical region was gated to the central $50 \mu \mathrm{m}^{2}$ of the sputter region

Hall Bar Fabrication and Magnetotransport Measurements. Arsenic delta layer samples were fabricated into 6 terminal Hall bars using standard UV photolithography, with electrical contact made via aluminum thermally evaporated over the edge of the mesa structures. Magnetotransport measurements were made at a temperature of $5 \mathrm{~K}$ in a Cryogenics Ltd. cryogen free measurement system using magnetic fields up to $5 \mathrm{~T}$. Details of these measurements, and quantification of the delta layer electrical transport characteristics, are explained in detail in the Supporting Information. 


\section{ASSOCIATED CONTENT}

\section{(s) Supporting Information}

The Supporting Information is available free of charge at https://pubs.acs.org/doi/10.1021/acsnano.9b08943.

Kinetic Monte Carlo calculations and magnetotransport data analysis (PDF)

\section{AUTHOR INFORMATION}

\section{Corresponding Authors}

Taylor J. Z. Stock - London Centre for Nanotechnology, University College London, London WC1H OAH, U.K.; 구 orcid.org/0000-0003-4164-362X; Email: t.stock@ ucl.ac.uk

Neil J. Curson - London Centre for Nanotechnology and Department of Electronic and Electrical Engineering, University

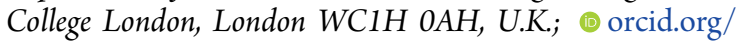
0000-0002-5661-0559; Email: n.curson@ucl.ac.uk

\section{Authors}

Oliver Warschkow - Centre for Quantum Computation and Communication Technology, School of Physics, The University of Sydney, Sydney, NSW 2006, Australia

Procopios C. Constantinou - London Centre for Nanotechnology, University College London, London $\mathrm{WC1H}$ OAH, U.K.

Juerong Li - Advanced Technology Institute, University of Surrey, Guildford GU2 7XH, U.K.

Sarah Fearn - London Centre for Nanotechnology, University College London, London WC1H OAH, U.K.; Department of Materials, Imperial College of London, London SW7 2AZ, U.K.

Eleanor Crane - London Centre for Nanotechnology, University College London, London WC1H OAH, U.K.

Emily V. S. Hofmann - London Centre for Nanotechnology, University College London, London WC1H OAH, U.K.; IHP Leibniz-Institut für Innovative Mikroelektronik, Frankfurt (Oder) 15236, Germany

Alexander Kölker - London Centre for Nanotechnology, University College London, London WC1H OAH, U.K.

David R. McKenzie - Centre for Quantum Computation and Communication Technology, School of Physics, The University of Sydney, Sydney, NSW 2006, Australia

Steven R. Schofield - London Centre for Nanotechnology and Department of Physics and Astronomy, University College

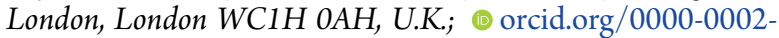
0727-3015

Complete contact information is available at: https://pubs.acs.org/10.1021/acsnano.9b08943

\section{Notes}

The authors declare no competing financial interest.

A preprint of this work has been posted: Stock, T. J. Z.; Warschkow, O; Constantinou, P. C.; Li, J; Fearn, S; Crane, E; Hofmann, E. V. S.; Kölker, A; McKenzie, D. R.; Schofield, S. R.; Curson, N. J. Atomic-Scale Patterning of Arsenic in Silicon by Scanning Tunneling Microscopy. arXiv, October 15, 2019, 1910.06685 [physics.app-ph]. https://arxiv.org/abs/1910. 06685.

All data created during this research are openly available at zenodo.org

\section{ACKNOWLEDGMENTS}

This project has been supported by the EPSRC project Atomically Deterministic Doping and Readout For Semiconductor Solotronics (grant number EP/M009564/1). P.C.C. and E.V.S.H. were partly supported by the EPSRC Centre for Doctoral Training in Advanced Characterisation of Materials (grant number EP/L015277/1), and also by Paul Scherrer Institute and IHP - Leibniz-Institut für Innovative Mikroelektronik, respectively. O.W. acknowledges the support of the Australian Research Council (ARC) Centre of Excellence for Quantum Computation and Communication Technology (project number CE110001027). Computing support was provided by the Australian National Computational Infrastructure (NCI).

\section{REFERENCES}

(1) Jehl, X.; Niquet, Y. M.; Sanquer, M. Single Donor Electronics and Quantum Functionalities with Advanced CMOS Technology. J. Phys.: Condens. Matter 2016, 28, 103001.

(2) Morton, J. J. L.; McCamey, D. R.; Eriksson, M. A.; Lyon, S. A. Embracing the Quantum Limit in Silicon Computing. Nature 2011, 479, 345-353.

(3) Schofield, S. R.; Curson, N. J.; Simmons, M. Y.; Rueß, F. J.; Hallam, T.; Oberbeck, L.; Clark, R. G. Atomically Precise Placement of Single Dopants in Si. Phys. Rev. Lett. 2003, 91, 136104.

(4) Hudak, B. M.; Song, J.; Sims, H.; Troparevsky, M. C.; Humble, T. S.; Pantelides, S. T.; Snijders, P. C.; Lupini, A. R. Directed Atomby-Atom Assembly of Dopants in Silicon. ACS Nano 2018, 12, 58735879 .

(5) Sinthiptharakoon, K.; Schofield, S. R.; Studer, P.; Brázdová, V.; Hirjibehedin, C. F.; Bowler, D. R.; Curson, N. J. Investigating Individual Arsenic Dopant Atoms in Silicon Using Low-Temperature Scanning Tunnelling Microscopy. J. Phys.: Condens. Matter 2014, 26, No. 012001

(6) Salfi, J.; Mol, J. A.; Rahman, R.; Klimeck, G.; Simmons, M. Y.; Hollenberg, L. C. L.; Rogge, S. Spatially Resolving Valley Quantum Interference of a Donor in Silicon. Nat. Mater. 2014, 13, 605-610.

(7) Voisin, B.; Salfi, J.; Bocquel, J.; Rahman, R.; Rogge, S. Spatially Resolved Resonant Tunneling on Single Atoms in Silicon. J. Phys.: Condens. Matter 2015, 27, 154203.

(8) Salfi, J.; Mol, J. A.; Rahman, R.; Klimeck, G.; Simmons, M. Y.; Hollenberg, L. C. L.; Rogge, S. Quantum Simulation of the Hubbard Model with Dopant Atoms in Silicon. Nat. Commun. 2016, 7, 11342.

(9) Pierre, M.; Wacquez, R.; Jehl, X.; Sanquer, M.; Vinet, M.; Cueto, O. Single-Donor Ionization Energies in a Nanoscale CMOS Channel. Nat. Nanotechnol. 2010, 5, 133-137.

(10) Greenland, P. T.; Lynch, S. A.; Van Der Meer, A. F. G.; Murdin, B. N.; Pidgeon, C. R.; Redlich, B.; Vinh, N. Q.; Aeppli, G. Coherent Control of Rydberg States in Silicon. Nature 2010, 465, 1057-1061.

(11) Li, J.; Le, N. H.; Litvinenko, K. L.; Clowes, S. K.; Engelkamp, H.; Pavlov, S. G.; Hübers, H. W.; Shuman, V. B.; Portsel, L. D.; Lodygin, D. N.; Astrov, Y. A.; Abrosimov, N. V.; Pidgeon, C. R.; Fisher, A.; Zeng, Z.; Niquet, Y. M.; Murdin, B. N. Radii of Rydberg States of Isolated Silicon Donors. Phys. Rev. B: Condens. Matter Mater. Phys. 2018, 98, No. 085423.

(12) Moraru, D.; Udhiarto, A.; Anwar, M.; Nowak, R.; Jablonski, R.; Hamid, E.; Tarido, J.; Mizuno, T.; Tabe, M. Atom Devices Based on Single Dopants in Silicon Nanostructures. Nanoscale Res. Lett. 2011, 6, 479.

(13) Warschkow, O.; Curson, N. J.; Schofield, S. R.; Marks, N. A.; Wilson, H. F.; Radny, M. W.; Smith, P. V.; Reusch, T. C. G. G.; McKenzie, D. R.; Simmons, M. Y. Reaction Paths of Phosphine Dissociation on Silicon (001). J. Chem. Phys. 2016, 144, No. 014705.

(14) Lyding, J. W.; Shen, T. C.; Hubacek, J. S.; Tucker, J. R.; Abeln, G. C. Nanoscale Patterning and Oxidation of H-Passivated Si(100)-2 
$\times 1$ Surfaces with an Ultrahigh Vacuum Scanning Tunneling Microscope. Appl. Phys. Lett. 1994, 64, 2010-2012.

(15) Koch, M.; Keizer, J. G.; Pakkiam, P.; Keith, D.; House, M. G.; Peretz, E.; Simmons, M. Y. Spin Read-Out in Atomic Qubits in an AllEpitaxial Three-Dimensional Transistor. Nat. Nanotechnol. 2019, 14, 137-140.

(16) Fuechsle, M.; Miwa, J. A.; Mahapatra, S.; Ryu, H.; Lee, S.; Warschkow, O.; Hollenberg, L. C. L.; Klimeck, G.; Simmons, M. Y. A Single-Atom Transistor. Nat. Nanotechnol. 2012, 7, 242-246.

(17) Wyrick, J.; Wang, X.; Kashid, R. V.; Namboodiri, P.; Schmucker, S. W.; Hagmann, J. A.; Liu, K.; Stewart, M. D.; Richter, C. A.; Bryant, G. W.; Silver, R. M. Atom-by-Atom Fabrication of Single and Few Dopant Quantum Devices. Adv. Funct. Mater. 2019, 1903475, 1903475.

(18) Hile, S. J.; Fricke, L.; House, M. G.; Peretz, E.; Chen, C. Y.; Wang, Y.; Broome, M.; Gorman, S. K.; Keizer, J. G.; Rahman, R.; Simmons, M. Y. Addressable Electron Spin Resonance Using Donors and Donor Molecules in Silicon. Sci. Adv. 2018, 4, No. eaaq1459.

(19) He, Y.; Gorman, S. K.; Keith, D.; Kranz, L.; Keizer, J. G.; Simmons, M. Y. A Two-Qubit Gate between Phosphorus Donor Electrons in Silicon. Nature 2019, 571, 371-375.

(20) Kane, B. E. A Silicon-Based Nuclear Spin Quantum Computer. Nature 1998, 393, 133-137.

(21) Morello, A.; Escott, C. C.; Huebl, H.; Willems Van Beveren, L. H.; Hollenberg, L. C. L.; Jamieson, D. N.; Dzurak, A. S.; Clark, R. G. Architecture for High-Sensitivity Single-Shot Readout and Control of the Electron Spin of Individual Donors in Silicon. Phys. Rev. B: Condens. Matter Mater. Phys. 2009, 80, No. 081307.

(22) Hill, C. D.; Peretz, E.; Hile, S. J.; House, M. G.; Fuechsle, M.; Rogge, S.; Simmons, M. Y.; Hollenberg, L. C. L. Quantum Computing: A Surface Code Quantum Computer in Silicon. Sci. Adv. 2015, 1, 1-12.

(23) Solmi, S.; Nobili, D. High Concentration Diffusivity and Clustering of Arsenic and Phosphorus in Silicon. J. Appl. Phys. 1998, 83, 2484-2490.

(24) Ramdas, A. K.; Rodriguez, S. Spectroscopy of the Solid-State Analogues of the Hydrogen Atom: Donors and Acceptors in Semiconductors. Rep. Prog. Phys. 1981, 44, 1297-1387.

(25) Slater, J. C. Atomic Radii in Crystals. J. Chem. Phys. 1964, 41, 3199-3204.

(26) Abanto, M.; Davidovich, L.; Koiller, B.; De Matos Filho, R. L. Quantum Computation with Doped Silicon Cavities. Phys. Rev. B: Condens. Matter Mater. Phys. 2010, 81, No. 085325.

(27) Salvail, J. Z.; Dluhy, P.; Morse, K. J.; Szech, M.; Saeedi, K.; Huber, J.; Riemann, H.; Abrosimov, N. V.; Becker, P.; Pohl, H. J.; Thewalt, M. L. W. Optically Enabled Magnetic Resonance Study of As 75 and Sb 121 in Si 28. Phys. Rev. B: Condens. Matter Mater. Phys. 2015, 92, 195203 .

(28) Franke, D. P.; Pflüger, M. P. D.; Itoh, K. M.; Brandt, M. S. Multiple-Quantum Transitions and Charge-Induced Decoherence of Donor Nuclear Spins in Silicon. Phys. Rev. Lett. 2017, 118, 246401.

(29) Franke, D. P.; Hrubesch, F. M.; Künzl, M.; Becker, H. W.; Itoh, K. M.; Stutzmann, M.; Hoehne, F.; Dreher, L.; Brandt, M. S. Interaction of Strain and Nuclear Spins in Silicon: Quadrupolar Effects on Ionized Donors. Phys. Rev. Lett. 2015, DOI: 10.1103/ PhysRevLett.115.057601.

(30) Lanyon, B. P.; Barbieri, M.; Almeida, M. P.; Jennewein, T.; Ralph, T. C.; Resch, K. J.; Pryde, G. J.; O’Brien, J. L.; Gilchrist, A.; White, A. G. Simplifying Quantum Logic Using Higher-Dimensional Hilbert Spaces. Nat. Phys. 2009, 5, 134-140.

(31) Neeley, M.; Ansmann, M.; Bialczak, R. C.; Hofheinz, M.; Lucero, E.; O'Connell, A. D.; Sank, D.; Wang, H.; Wenner, J.; Cleland, A. N.; Geller, M. R.; Martinis, J. M. Emulation of a Quantum Spin with a Superconducting Phase Qudit. Science 2009, 325, 722725.

(32) Stoneham, A. M.; Fisher, A. J.; Greenland, P. T. Optically Driven Silicon-Based Quantum Gates with Potential for HighTemperature Operation. J. Phys.: Condens. Matter 2003, 15, 447-451.
(33) Kipp, L.; Bringans, R. D.; Biegelsen, D. K.; Swartz, L. E.; Hicks, R. F. Arsine Adsorption on $\mathrm{Si}(100) 2 \times 1$ : A Photoemission and Scanning-Tunneling-Microscopy Study. Phys. Rev. B: Condens. Matter Mater. Phys. 1994, 50, 5448-5455.

(34) Tok, E. S.; Hartell, A. D.; Zhang, J. Kinetics of Si Growth from Hydride Precursors on As-Passivated Si(001) Surface. Appl. Phys. Lett. 2001, 78, 919-921.

(35) Soares, J. A. N. T.; Kim, H.; Glass, G.; Desjardins, P.; Greene, J. E. Arsenic-Doped $\mathrm{Si}(001)$ Gas-Source Molecular-Beam Epitaxy: Growth Kinetics and Transport Properties. Appl. Phys. Lett. 1999, $74,1290-1292$.

(36) Cho, J.; Ghosh, M. K.; Choi, C. H. Adsorption Reactions of Trimethylgallium and Arsine on $\mathrm{H} / \mathrm{Si}(100)-2 \times 1$ Surface. Bull. Korean Chem. Soc. 2009, 30, 1805-1810.

(37) Kim, H.; Glass, G.; Soares, J. A. N. T.; Desjardins, P.; Greene, J. E. Arsenic Incorporation during $\mathrm{Si}(001)$ :As Gas-Source MolecularBeam Epitaxy from $\mathrm{Si}_{2} \mathrm{H}_{6}$ and $\mathrm{AsH}_{3}$ : Effects on Film-Growth Kinetics. J. Appl. Phys. 2000, 88, 7067-7078.

(38) Kim, H.; Glass, G.; Soares, J. A. N. T.; Foo, Y. L.; Desjardins, P.; Greene, J. E. Temperature-Modulated $\mathrm{Si}(001)$ :As Gas-Source Molecular Beam Epitaxy: Growth Kinetics and As Incorporation. Appl. Phys. Lett. 2001, 79, 3263-3265.

(39) Oberbeck, L.; Curson, N. J.; Hallam, T.; Simmons, M. Y.; Bilger, G.; Clark, R. G. Measurement of Phosphorus Segregation in Silicon at the Atomic Scale Using Scanning Tunneling Microscopy. Appl. Phys. Lett. 2004, 85, 1359-1361.

(40) Oberbeck, L.; Curson, N. J.; Simmons, M. Y.; Brenner, R.; Hamilton, A. R.; Schofield, S. R.; Clark, R. G. Encapsulation of Phosphorus Dopants in Silicon for the Fabrication of a Quantum Computer. Appl. Phys. Lett. 2002, 81, 3197-3199.

(41) Northrup, J. E. Theoretical Studies of Arsine Adsorption on Si(100). Phys. Rev. B: Condens. Matter Mater. Phys. 1995, 51, 22182222.

(42) Miotto, R.; Srivastava, G. P.; Miwa, R. H.; Ferraz, A. C. A Comparative Study of Dissociative Adsorption of NH3, PH3, and AsH3 on Si(001)- $(2 \times 1)$. J. Chem. Phys. 2001, 114, 9549-9556.

(43) McDonell, T. L.; Marks, N. A.; Warschkow, O.; Wilson, H. F.; Smith, P. V.; Radny, M. W. Molecular Dissociation of Group-V Hydrides on Si(001). Phys. Rev. B: Condens. Matter Mater. Phys. 2005, 72, 193307.

(44) Škereň, T.; Köster, S.; Douhard, B.; Fleischmann, C.; Fuhrer, A. P-Type $\delta$-Doping with Diborane on $\mathrm{Si}(001)$ for STM Based Dopant Device Fabrication.arXiv(Condensed Matter.Mesoscale and Nanoscale Physics), December 12, 2019, 1912.06188 ver. 1. https://arxiv.org/ abs/1912.06188 (accessed 2019-12-23).

(45) Hamers, R. J.; Köhler, U. K. Determination of the Local Electronic Structure of Atomic-Sized Defects on $\mathrm{Si}(001)$ by Tunneling Spectroscopy. J. Vac. Sci. Technol., A 1989, 7, 2854-2859.

(46) Warschkow, O.; Schofield, S.; Marks, N.; Radny, M.; Smith, P.; McKenzie, D. Water on Silicon (001): C Defects and Initial Steps of Surface Oxidation. Phys. Rev. B: Condens. Matter Mater. Phys. 2008, 77,201305

(47) Wilson, H. F.; Warschkow, O.; Marks, N. A.; Schofield, S. R.; Curson, N. J.; Smith, P. V.; Radny, M. W.; McKenzie, D. R.; Simmons, M. Y. Phosphine Dissociation on the Si(001) Surface. Phys. Rev. Lett. 2004, 93, 226102.

(48) Curson, N. J.; Schofield, S. R.; Simmons, M. Y.; Oberbeck, L.; O'Brien, J. L.; Clark, R. G. STM Characterization of the Si-P Heterodimer. Phys. Rev. B: Condens. Matter Mater. Phys. 2004, 69, 195303.

(49) McKibbin, S. R.; Clarke, W. R.; Fuhrer, A.; Reusch, T. C. G.; Simmons, M. Y. Investigating the Regrowth Surface of Si:P $\delta$-Layers toward Vertically Stacked Three Dimensional Devices. Appl. Phys. Lett. 2009, 95, 233111.

(50) Schofield, S. R.; Curson, N. J.; Warschkow, O.; Marks, N. A.; Wilson, H. F.; Simmons, M. Y.; Smith, P. V.; Radny, M. W.; McKenzie, D. R.; Clark, R. G. Phosphine Dissociation and Diffusion on $\mathrm{Si}(001)$ Observed at the Atomic Scale. J. Phys. Chem. B 2006, 110, 3173-3179. 
(51) Wilson, H. F.; Warschkow, O.; Marks, N. A.; Curson, N. J.; Schofield, S. R.; Reusch, T. C. G.; Radny, M. W.; Smith, P. V.; McKenzie, D. R.; Simmons, M. Y. Thermal Dissociation and Desorption of $\mathrm{PH} 3$ on $\mathrm{Si}(001)$ : A Reinterpretation of Spectroscopic Data. Phys. Rev. B: Condens. Matter Mater. Phys. 2006, 74, 656-661.

(52) Lin, D. S.; Ku, T. S.; Sheu, T. J. Thermal Reactions of Phosphine with $\mathrm{Si}(100)$ : A Combined Photoemission and ScanningTunneling-Microscopy Study. Surf. Sci. 1999, 424, 7-18.

(53) Liu, X.; Tang, Q.; Kamins, T. I.; Harris, J. S. Heavy Arsenic Doping of Silicon by Molecular Beam Epitaxy. J. Cryst. Growth 2003, 251, 651-656.

(54) Bashir, R.; Kabir, A. E.; Westrom, P. Phosphorus and Arsenic Profile Control for High Performance Epitaxial Base Bipolar Junction Devices. Appl. Phys. Lett. 1999, 75, 796-798.

(55) Barnett, S. A.; Greene, J. E. Si Molecular Beam Epitaxy: A Model for Temperature Dependent Incorporation Probabilities and Depth Distributions of Dopants Exhibiting Strong Surface Segregation. Surf. Sci. 1985, 151, 67-90.

(56) Liu, X.; Tang, Q.; Harris, J. S.; Kamins, T. I. Arsenic Surface Segregation during In Situ Doped Silicon and $\mathrm{Si}_{1-\mathrm{x}} \mathrm{Ge}_{\mathrm{x}}$ Molecular Beam Epitaxy. J. Cryst. Growth 2005, 281, 334-343.

(57) Eaglesham, D. J. Semiconductor Molecular-Beam Epitaxy at Low Temperatures. J. Appl. Phys. 1995, 77, 3597-3617.

(58) Scappucci, G.; Klesse, W. M.; Hamilton, A. R.; Capellini, G.; Jaeger, D. L.; Bischof, M. R.; Reidy, R. F.; Gorman, B. P.; Simmons, M. Y. Stacking of $2 \mathrm{D}$ Electron Gases in Ge Probed at the Atomic Level and Its Correlation to Low-Temperature Magnetotransport. Nano Lett. 2012, 12, 4953-4959.

(59) Scappucci, G.; Capellini, G.; Johnston, B.; Klesse, W. M.; Miwa, J. A.; Simmons, M. Y. A Complete Fabrication Route for AtomicScale, Donor-Based Devices in Single-Crystal Germanium. Nano Lett. 2011, 11, 2272-2279.

(60) Scappucci, G.; Capellini, G.; Klesse, W. M.; Simmons, M. Y. Dual-Temperature Encapsulation of Phosphorus in Germanium $\delta$ layers toward Ultra-Shallow Junctions. J. Cryst. Growth 2011, 316, $81-84$.

(61) Keizer, J. G.; Koelling, S.; Koenraad, P. M.; Simmons, M. Y. Suppressing Segregation in Highly Phosphorus Doped Silicon Monolayers. ACS Nano 2015, 9, 12537-12541.

(62) Wang, X.; Hagmann, J. A.; Namboodiri, P.; Wyrick, J.; Li, K.; Murray, R. E.; Myers, A.; Misenkosen, F.; Stewart, M. D.; Richter, C. A.; Silver, R. M. Quantifying Atom-Scale Dopant Movement and Electrical Activation in Si:P Monolayers. Nanoscale 2018, 10, 44884499.

(63) Hagmann, J. A.; Wang, X.; Namboodiri, P.; Wyrick, J.; Murray, R.; Stewart, M. D.; Silver, R. M.; Richter, C. A. High Resolution Thickness Measurements of Ultrathin Si:P Monolayers Using Weak Localization. Appl. Phys. Lett. 2018, 112, No. 043102.

(64) Berding, M. A.; Sher, A.; Van Schilfgaarde, M.; Rousseau, P. M.; Spicer, W. E. Deactivation in Heavily Arsenic-Doped Silicon. Appl. Phys. Lett. 1998, 72, 1492-1494.

(65) Duguay, S.; Vurpillot, F.; Philippe, T.; Cadel, E.; Lardé, R.; Deconihout, B.; Servanton, G.; Pantel, R. Evidence of Atomic-Scale Arsenic Clustering in Highly Doped Silicon. J. Appl. Phys. 2009, 106, 106102.

(66) Frisch, M. J.; Trucks, G. W.; Schlegel, H. B.; Scuseria, G. E.; Robb, M. A.; Cheeseman, J. R.; Scalmani, G.; Barone, V.; Mennucci, B.; Petersson, G. A.; Nakatsuji, H.; Caricato, M.; Li, X.; Hratchian, H. P.; Izmaylov, A. F.; Bloino, J.; Zheng, G.; Sonnenberg, J. L.; Hada, M.; Ehara, M.;et al. Gaussian 09, rev. E.01; Gaussian Inc.: Wallingford, CT, 2013.

(67) Warschkow, O.; Gao, I.; Schofield, S. R.; Belcher, D. R.; Radny, M. W.; Saraireh, S. A.; Smith, P. V. Acetone on Silicon (001): Ambiphilic Molecule Meets Ambiphilic Surface. Phys. Chem. Chem. Phys. 2009, 11, 2747-2759.

(68) Schofield, S. R.; Warschkow, O.; Belcher, D. R.; Rahnejat, K. A.; Radny, M. W.; Smith, P. V. Phenyl Attachment to Si(001) via STM Manipulation of Acetophenone. J. Phys. Chem. C 2013, 117, 5736-5741.
(69) Belcher, D. R.; Schofield, S. R.; Warschkow, O.; Radny, M. W.; Smith, P. V. Carbonyl Mediated Attachment to Silicon: Acetaldehyde on Si(001). J. Chem. Phys. 2009, 131, 104707. 